01

\title{
Наблюдение квантовых биений двухфотонно возбужденных состояний атомов Хе при фотоионизации
}

\author{
(C) Е.А. Викторов, А.А. Пастор, П.Ю. Сердобинцев, Н.Н. Безуглов \\ Санкт-Петербургский государственный университет, \\ 199034 Санкт-Петербург, Россия \\ e-mail: eaviktorov@yandex.com
}

Поступила в редакцию 21.03.2021 г.

В окончательной редакции 23.04.2021 г.

Принята к публикации 19.05.2021 г.

Исследована ионизация когерентно двухфотонно возбужденной суперпозиции $4 f$-состояний атома Хе фемтосекундным импульсом пробного лазера в сверхзвуковом пучке с регулируемой задержкой между импульсами накачки и пробным. Регистрируемая колебательная структура в сигналах фотоионизации связана с когерентными биениями суперпозиции возбужденных состояний. Высокая эффективность предложенной схемы регистрации квантовых биений обусловлена практически 100\%-й эффективностью сбора фотоэлектронов в отличие от ранее используемой регистрации флуоресценции.

Ключевые слова: квантовые биения, двухфотонное возбуждение, фемтосекундная ионизация.

DOI: $10.21883 /$ OS.2021.09.51335.2038-21

\section{Введение}

Исследование характеристик флуоресценции при возбуждении ориентированных состояний атомов поляризованным светом составляет важный раздел современной спектроскопии, призванный существенным образом расширить возможности оптической диагностики газовых сред $[1,2]$. Наблюдение магнитных резонансов лежит в основе конструирования и реализации чувствительных магнитометров $[3,4]$. Появление различных типов периодической структуры при регистрации интенсивности рассеянного света в присутствии магнитного поля позволяет осуществлять прецизионные измерения параметров атомных состояний в обход ограничений, накладываемых явлением допплеровского уширения линий. Традиционные методы спектроскопии связаны с возбуждением связанно-связанных оптических переходов [1,3]. В предыдущей публикации [5] авторами наблюдались квантовые биения при фотоионизации магнитных подуровней ряда трехфотонно возбужденных состояний $\mathrm{Ar}$ с использованием импульсов с круговой поляризацией. Это дало возможность определения $g$-факторов данных состояний по измерению периодов ларморовской прецессии в магнитном поле. В настоящем кратком сообщении мы экспериментально демонстрируем возможность наблюдения осцилляций фототоков при фотоионизации когерентных атомных состояний атомов Хе в сверхзвуковом пучке, возбуждаемых широкополосным фемтосекундным лазерным импульсом. Фотоэлектронная спектроскопия для диагностики параметров квантовых состояний [6] имеет ряд важных преимуществ по сравнению с оптической диагностикой в связи с почти 100\%-й эффективностью сбора фотоэлектронов из зоны взаимодействия. В нашем эксперименте двухфотонно возбужденная суперпозиция двух близко расположенных возбужденных состояний атома Хе фотоионизуется пробным импульсом фемтосекундного лазера с регулируемой задержкой. Наблюдаемые осцилляции тока фотоэлектронов соответствуют периоду когерентных биений суперпозиции состояний, созданной импульсом накачки.

\section{Эксперимент}

В настоящей работе сверхзвуковой пучок атомов Хе пересекает сфокусированный лазерный луч, состоящий из последовательности двух импульсов: УФ импульса накачки с длиной волны $220 \mathrm{~nm}$ и пробного ИК импульса. Мы используем „рump-probe“ эксперимент с двухфотонным возбуждением атомов Хе в близлежащие состояния $5 p^{5}\left({ }^{2} P_{3 / 2}\right) 4 f[3 / 2]_{2}$ и $5 p^{5}\left({ }^{2} P_{3 / 2}\right) 4 f[5 / 2]_{2}$ с помощью импульса накачки. Возбуждение осуществляется излучением оптического параметрического усилителя (ОРА) с горизонтальной поляризацией на длине волны около $220 \mathrm{~nm}$. Фотоионизация возбужденных атомов осуществляется пробным импульсом титан-сапфирового фемтосекундного лазера с горизонтальной поляризацией на длине волны $795 \mathrm{~nm}$, спектральная ширина импульса ионизации больше расстояния между данными $4 f$ уровнями.

Для регистрации энергетических спектров использовался электронный спектрометр типа „магнитная бутылка“. Анализ энергетических спектров электронов, полученных при различных задержках пробного импульса относительно импульса накачки, позволил получить данные о квантовых биениях. Энергетические спектры дают информацию о уровнях, с которых шла ионизация, и о интенсивности ионизации с данных уровней. Схема экспериментальной установки приведена на рис. 1. 


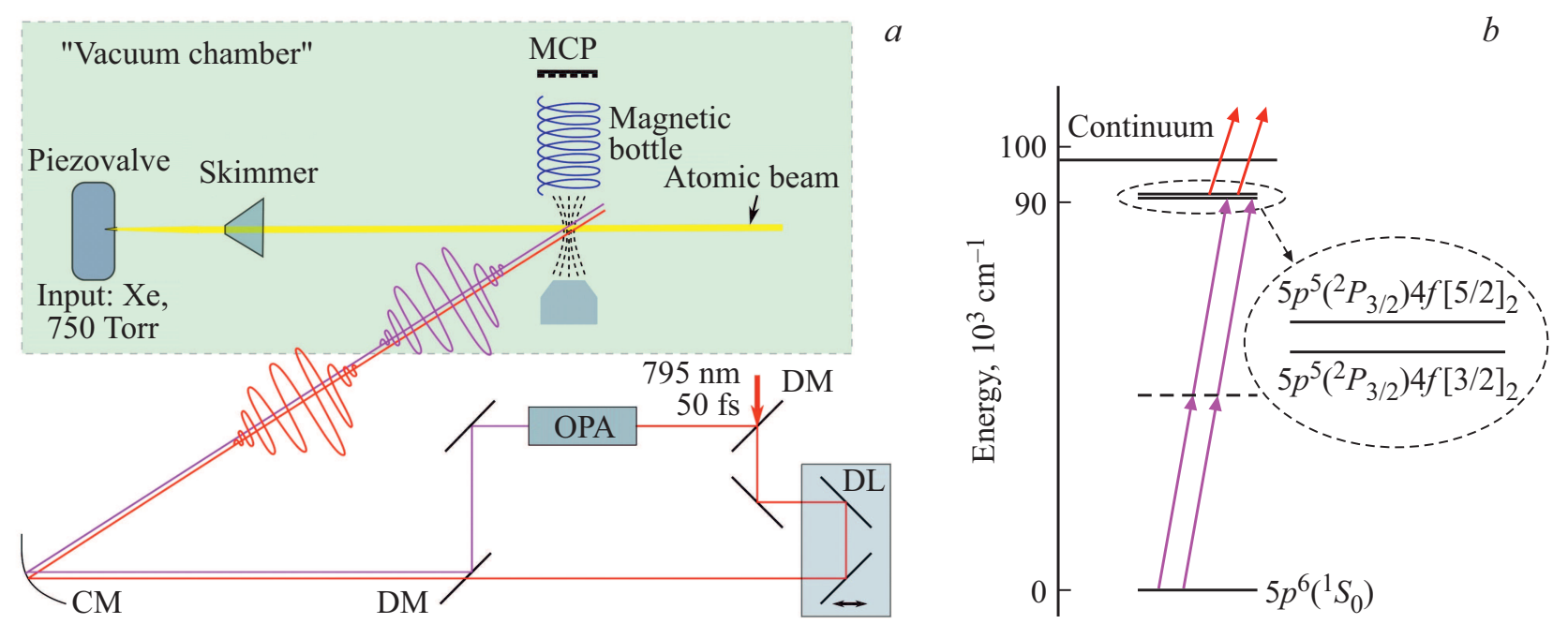

Рис. 1. (а) Экспериментальная установка: OPA - оптический параметрический усилитель; DL - линия задержки; DM дихроичное зеркало; СМ - вогнутое зеркало; МСР - микроканальная пластина. (b) Возбуждаемые $4 f$-уровни Хе.

Для создания сверхзвукового пучка атомов используется пьезоэлектрический клапан, который впрыскивает ксенон, находящийся под давлением 750 Torr, в вакуумную камеру, откачанную до давления $10^{-5}$ Torr. В результате адиабатического расширения газа, выходящего из сопла диаметром $200 \mu \mathrm{m}$ при комнатной температуре, атомы Хе формируют сверхзвуковой пучок. Пролетев $20 \mathrm{~mm}$, атомы проходят через скиммер диаметром $1.5 \mathrm{~mm}$. На расстоянии $100 \mathrm{~mm}$ от сопла сверхзвуковой пучок атомов пересекает сфокусированный лазерный луч. Пробный импульс и импульс накачки фокусировались в зону взаимодействия вогнутым зеркалом.

Для эксперимента используется излучение титансапфирового фемтосекундного лазера „Пульсар-10“ со следующими характеристиками: основная длина волны $-795 \mathrm{~nm}$, энергия импульса $-5 \mathrm{~mJ}$, длительность импульса $-50 \mathrm{fs}$, частота повторения $-10 \mathrm{~Hz}$.

Импульс лазера делится на две части: $70 \%$ энергии поступает на параметрический усилитель ТОПАС и преобразуется в УФ излучение для многофотонного возбуждения атомных состояний, оставшиеся $30 \%$ энергии импульса используется как первая гармоника для ионизации уже возбужденных атомов. Корреляционная функция импульса накачки и пробного импульса измеряется по сигналу нерезонансной многофотонной ионизации, ее полуширина на полувысоте составляет $140 \mathrm{fs}$ (FWHM). Для нерезонансной многофотонной ионизации берутся такие длины волн накачки и возбуждения, которые не совпадают с какими-либо резонансами атома. При облучении атомов наблюдается сигнал фотоионизации с энергией свободных электронов, равной сумме энергии двух фотонов возбуждения и энергии фотона ионизации минус потенциал ионизации атома. Сигнал существует только при временном перекрытии импульса накачки и импульса возбуждения. Изменение задержки позво-

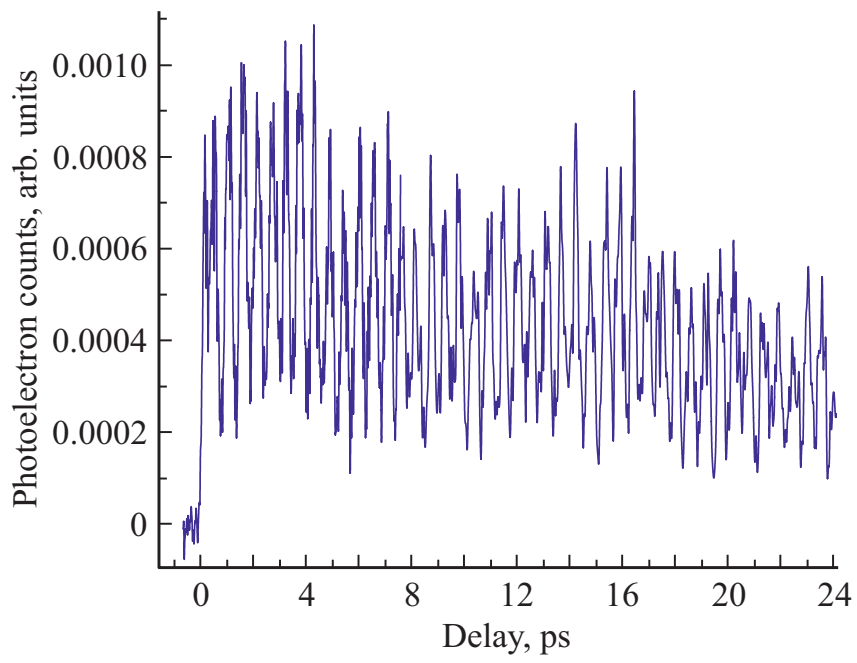

Рис. 2. Зависимость фототока от времени задержки.

ляет прописывать корреляционную функцию импульса накачки и пробного импульса. Временное разрешение равно ширине корреляционной функции на полувысоте (FWHM).

Для регулирования времени задержки между импульсами при резонансной фотоионизации использовалась оптическая система. По мере изменения задержки появляются периодические осцилляции интенсивности тока фотоэлектронов с энергией $E_{2}$ на разностной частоте уровней $\Delta \omega$ (рис. 2), равной частотному расстоянию между этими уровнями $\Delta \omega=\omega_{5 / 2}-\omega_{3 / 2}$. Энергия $E_{2}=0.95 \mathrm{eV}$ соответствует ионизации исследуемых $4 f$ уровней двумя фотонами пробного излучения с образованием иона $\mathrm{Xe}^{+}\left(5 s^{2} 5 p^{52} P_{1 / 2}^{\circ}\right)$. Причиной осцилляции тока фотоэлектронов являются квантовые биения двухфотонно возбужденной суперпозиции уровней ксенона. 
Из экспериментальных данных, приведенных на рис. 2, мы имеем период биений, равный 0.549 ps, что хорошо согласуется с периодом квантовых биений суперпозиции двух возбуждаемых нами уровней Хе. Расстояние между уровнями в обратных сантиметpax $\Delta \tilde{v}=60.612 \mathrm{~cm}^{-1}$, период биений должен быть $T=1 / \Delta \tilde{v} c=0.55 \mathrm{ps}$, где $c-$ скорость света.

\section{Заключение}

В заключение отметим, что в работе экспериментально продемонстрировано явление квантовых биений в виде осцилляций интегрального фототока электронов с энергией $\sim 0.95 \mathrm{eV}$, которое обусловлено интерференцией когерентных квантовых состояний. Данный эффект позволяет осуществлять измерения параметров атомных состояний, избегая ограничений, накладываемых традиционными методами исследования флуоресценции. Обратим также внимание, что при всей схожести проявления интерференций когерентности в сигналах флуоресценции и фотоионизации теоретическое описание для последнего случая следует проводить в рамках теории Фано [7] для $\Lambda$-схемы возбуждения, верхний уровень которой лежит в континууме энергий.

\section{Благодарности}

Эксперимент был выполнен с использованием оборудования Ресурсного центра СПбГУ „Физические методы исследования поверхности“.

\section{Конфликт интересов}

Авторы заявляют, что у них нет конфликта интересов.

\section{Список литературы}

[1] Auzinsh M., Budker D., Rochester S. Optically Polarized Atoms. Understanding light-atom interactions. Oxford University press, 2010.

[2] Sydoryk I., Bezuglov N.N., Beterov I.I., Miculis K., Saks E., Janovs A., Spels P., Ekers A. // Phys. Rev. A. 2008. V. 77. P. 042511. doi 10.1103/PhysRevA.77.042511

[3] Alexandrov E.B., Chaika M.P., Khvostenko G.I. Interference of Atomic States. Springer Series on Atoms and Plasmas. V. 7. Berlin: Springer, 1993.

[4] Alexandrov E.B., Auzinsh M., Budker D., Kimball D.F., Rochester S.M., Yashchuk V.V. // J. Opt. Soc. Am. B. 2005. V. 22. P. 7-20. doi 10.1364/JOSAB.22.000007

[5] Viktorov E.A., Bezuglov N.N., Klyucharev A.N., Pastor A.A., Serdobintsev P.Yu., Khodorkovskii M.A. // J. Phys.: Conf. Ser. 2020. V. 1695. P. 012098. doi 10.1088/1742-6596/1695/1/01209

[6] Porfido N., Bezuglov N.N., Bruvelis M., Shayeganrad G., Birindelli S., Tantussi F., Guerri I., Viteau M., Fioretti A., Ciampini D., Allegrini M., Arimondo E., Ekers A., Fuso F. // Phys. Rev. A. 2015. V. 92. P. 043408. doi 10.1103/PhysRevA.92.043408
[7] Fano U. // Phys. Rev. 1961. V. 124. P. 1866. doi 10.1103/PhysRev.124.1866 